and Lynettte Yaxley for help in initial development of the study and Michael Grande for statistical advice. RCT is guarantor for the study.

Funding: None.

Competing interests: None declared.

1 Casson IF, Clarke CA, Howard CV, McKendrick O, Pennycook S, Pharoah POD, et al. Outcomes of pregnancy in insulin dependent women: results of a five year cohort study. BMJ 1997;315:275-8.

2 Hawthorne G, Robson S, Ryall EA, Sen D, Roberts SH, Ward Platt MP. Prospective population based survey of outcome of pregnancy in diabetic women: results of the northern diabetic pregnancy audit, 1994. BMJ 1997;315:279-81.

3 Hanson U, Persson B, Thurnell S. Relationship between haemoglobin Alc in early type 1 (insulin-dependent) diabetic pregnancy and the occurrence of spontaneous abortion and fetal malformation in Sweden. Diabetologia 1990;33:100-4

4 Nielson GL, Sorensen PH, Nielson PH, Sabroe S, Olsen J. Glycosylated hemoglobin as predictor of adverse fetal outcome in type 1 diabetic pregnancies. Acta Diabetol 1997;34:217-22

5 Rosenn B, Miodovnik M, Combs CA, Khoury J, Siddiqi TA. Glycaemic thresholds for spontaneous abortions and congenital malformations in insulin-dependent diabetes mellitus. Obstet Gynecol 1994;84:515-20.

(Accepted 22 April 2002)

\title{
Observational study of type of surgical training and outcome of definitive surgery for primary malignant melanoma
}

\author{
Rona M MacKie, Caroline A Bray, David J Hole
}

Department of Public Health, University of Glasgow, Glasgow G12 8RZ

Rona M MacKie Leverhulme

professorial research fellow

Caroline A Bray medical statistician

David J Hole professor of epidemiology and biostatistics

Correspondence to R M MacKie R.M.Mackie@ clinmed.gla.ac.uk

BMJ 2002;325:1276-7
The incidence of primary cutaneous malignant melanoma continues to rise, ${ }^{1}$ coinciding with narrower excision margins of normal skin being recommended around primary melanomas. ${ }^{23}$ The bulk of surgery for primary melanoma is now done on an outpatient basis under local anaesthesia. This change has occurred at a time when training in dermatological surgery has developed, leading to a much higher proportion of excisions of primary melanoma being done by dermatologists. In 1979 in the west of Scotland only 3\% of all primary melanomas were removed by dermatologists. By 1998 this figure had risen to 40\%. Plastic surgeons now excise $26 \%$ of primary melanomas compared with $65 \% 20$ years ago, and general surgeons excise 34\% compared with $32 \%$.

We aimed to establish if the change in type of surgeon removing primary cutaneous malignant melanoma has affected the prognosis, and also whether any evidence exists for a specialist treatment effect such as has been observed for breast cancers, with better outcomes for surgeons carrying out breast cancer surgery regularly. ${ }^{4}$

\section{Participants, methods, and results}

We identified 4159 melanoma patients from the files of the Scottish melanoma group. All patients had had their primary melanoma removed between 1979 and 1998. We divided the surgeons performing the defini- tive excision of the primary melanoma into dermatological, plastic surgery, or general surgery training. We recorded age, sex, tumour thickness, presence of ulceration, and maximum diameter of the primary tumour and noted mortality and cause of death up to 1998. We also looked at the effect within the three surgical groups of treating up to six or more than six primary melanomas annually.

An average of 10 years' follow up information was available for all patients. To test for an association between tumour thickness and type of surgical experience we used the $\chi^{2}$ statistic for trend, aggregated over the period of diagnosis. We used the Cox proportional hazards model to compare the survival of patients in relation to surgical experience, ${ }^{5}$ with adjustment for thickness, ulceration, and maximum diameter of tumour and sex, age, and deprivation category of patients.

The table shows the division of patients by tumour thickness, ulceration, maximum diameter of primary melanoma, and outcome by surgical training. Dermatologists treated a significantly higher proportion of thin melanomas $(\mathrm{P}<0.001)$. The proportion of ulcerated melanomas was higher in the plastic surgery group than in the dermatological group $(\mathrm{P}<0.001)$ and higher in the general surgical group than the plastic surgery group $(\mathrm{P}<0.001)$.

After adjustment for thickness, the best outcome was in the dermatological surgeon treatment group

Details of melanomas treated, by surgical groups adjusted for type of surgical training. Values are numbers (percentages) unless stated otherwise

\begin{tabular}{|c|c|c|c|c|}
\hline Characteristics of melanomas & Dermatologist surgeon $(n=1076)$ & Plastic surgeon $(n=1691)$ & General surgeon $(n=1392)$ & Total $(n=4159)$ \\
\hline Primary tumours $<1.5 \mathrm{~mm}$ thick & $739(69)^{\star}$ & $809(48)$ & $589(42)$ & $2137(51)$ \\
\hline Primary tumours $1.5-3.49 \mathrm{~mm}$ thick & $217(20)$ & $447(26)$ & $342(25)$ & $1006(24)$ \\
\hline Primary tumours $\geqslant 3.5 \mathrm{~mm}$ thick & $120(11)$ & $435(26)$ & $461(33)$ & $1016(24)$ \\
\hline \multicolumn{5}{|l|}{ Relative hazard ratios† (95\% Cl) (risk of death) } \\
\hline Adjusted for thicknessł & 1.0 & 1.33 (1.07 to 1.65$)$ & 1.41 (1.14 to 1.75$)$ & $P=0.008$ \\
\hline Adjusted for thickness and ulceration & 1.0 & $1.22(0.97$ to 1.54$)$ & $1.23(0.97$ to 1.55$)$ & $\mathrm{P}=0.19$ \\
\hline
\end{tabular}

${ }^{*} \mathrm{P}<0.001$ for comparison of proportion of thin melanomas treated by dermatological surgeons compared with other surgeons; also for proportion of ulcerated melanomas both between dermatological and plastic surgeons and between plastic and general surgeons.

†Sex, age, deprivation category, and year of diagnosis were considered in the model but did not contribute any significant impact on surgical training differences.

¥Thickness of primary tumour has been entered as a stratification variable owing to non-proportionality of the hazard functions. 
$(\mathrm{P}=0.008)$. Statistical significance was lost when adjustment was made for ulceration and then for maximum diameter. We found no evidence that surgeons in any of the three categories who performed more than six primary melanoma excisions annually had better outcomes than those who performed fewer excisions.

\section{Comment}

Survival of melanoma patients does not depend on the surgical background of the person removing the primary tumour. The object of this study was to provide an evidence base for primary care guidelines on appropriate specialist referral. The data show that the growth in dermatological surgeons excising primary melanomas has had no adverse affect on patient outcome. We found no evidence that any type of surgeon performing excisions of primary melanomas regularly had a better outcome than those who carried out fewer excisions, possibly because wide local excision is a relatively simple procedure. We therefore provide an evidence base to recommend referral of suspected primary melanomas to the dermatological, plastic surgery, or general surgical service with the shortest surgical waiting time.

Contributors: RMM collected the data, wrote the paper, and is the guarantor for the study. $\mathrm{CAB}$ and $\mathrm{DJH}$ analysed the data.

Funding: The Scottish Melanoma Group is funded by NHS Scotland. RMM receives financial support from the Leverhulme Trust.

Conflicts of interest: None declared.

1 MacKie RM, Hole DJ, Hunter JAA, Rankin R, Evans A, McLaren K, et al. Cutaneous malignant melanoma in Scotland: incidence, survival, and mortality 1979-94. BMJ 1997;315:1117-21

2 Veronesi U, Cascinelli N, Adamus J, Balch C, Bandiera D, Barchuk A, et al. Thin stage I primary cutaneous malignant melanoma: comparison of excision with margins of 1 or $3 \mathrm{~cm}$. N Engl J Med 1988;318:1159-62.

3 Balch CM, Urist MM, Karakousis CP, Smith TJ, Temple WJ, Drzewiecki K, et al. Efficacy of 2-cm surgical margins for intermediate thickness melanomas (1 to $4 \mathrm{~mm}$ ): Results of a multi-institutional randomized surgical trial. Ann Surg 1993;218:262-8.

4 Sainsbury R, Haward B, Rider L, Johnston C, Round C. Influence of clinician workload and patterns of treatment on survival from breast cancer. Lancet 1995:345:1265-70.

5 Cox DR. Regression models and life tables. J R Stat Soc (B) 1972;34:187220

(Accepted 17 April 2002)

\section{Dysgeusia and burning mouth syndrome by eprosartan}

Xavier Castells, Isidre Rodoreda, Consuelo Pedrós, Gloria Cereza, Joan-Ramon Laporte

Eprosartan is an angiotensin II receptor antagonist. Dysgeusia and burning mouth syndrome attributed to angiotensin converting enzyme inhibitors have been reported. ${ }^{1}$ Several case reports related to angiotensin II receptor antagonists have also been published. We report the case of a patient in whom oral eprosartan induced reversible taste disturbance and burning mouth sensation on two occasions. This case was reported to the Catalan pharmacovigilance centre.

A 48 year old woman with a 10 year history of essential hypertension was being treated with valsartan $160 \mathrm{mg}$ daily. She had no other medical condition and was not taking any other drugs. She started taking eprosartan $600 \mathrm{mg}$ daily because her blood pressure remained uncontrolled with valsartan. Three weeks later she complained of a metallic taste and a burning sensation in her mouth. The oral cavity was normal and no underlying medical causes were identified. She stopped taking eprosartan and one week later her taste had returned to normal. The dysgeusia was not attributed to eprosartan and she started taking the drug again. A few days later, dysgeusia and the burning sensation in her mouth returned. She stopped taking eprosartan and her taste recovered in two days.

Taste disorders related to angiotensin II receptor antagonists had not been described in clinical trials, ${ }^{2}$ but several cases of dysgeusia have been reported in patients treated with losartan ${ }^{3-5}$ and with valsartan. ${ }^{6}$ To our knowledge, this is the first reported case of dysgeusia induced by eprosartan and the first case of dysgeusia induced by angiotensin II receptor antagonists with positive rechal- lenge. Dysgeusia with losartan but not with angiotensin converting enzyme inhibitors has been reported to occur in the same patient, suggesting that angiotensin converting enzyme inhibitors or angiotensin II receptor antagonists produce this effect by acting through different mechanisms. ${ }^{5}$ Because the incidence of dysgeusia in patients treated with drugs from these two therapeutic groups is low, ${ }^{12}$ it is possible that this adverse effect appears only in patients with some predisposing condition.

In our case report, the temporal sequence of eventsand, in particular, positive rechallenge-and the lack of underlying concomitant diseases or other drugs strongly suggest that the association between dysgeusia, burning mouth syndrome, and eprosartan was causal. Because these effects occurred with eprosartan but not with valsartan at equivalent doses, however, our observation does not favour the theory of an effect due to the angiotensin II receptor antagonist class of drug. Factors predisposing to this adverse effect remain to be identified and the mechanism remains to be elucidated.

Funding: Departament de Sanitat i Seguretat Social, Generalitat de Catalunya.

Competing interests: None declared.

1 Henkin RI. Drug-induced taste and smell disorders. Incidence, mechanisms and management related primarly to treatment of sensory receptor dysfunction. Drug Saf 1994;11:318-77.

2 Mazzolai L, Burnier M. Comparative safety and tolerability of angiotensin II-receptor antagonists. Drug Saf 1999;21:23-33.

3 Malnick SD, Becker S. Dysgeusia by losartan in a patient intolerant of captopril. Med Gen Med 1999;4:E33.

4 Schlienger RG, Saxer MS, Haefeli WE. Reversible dysgeusia associated with losartan. Lancet 1996;347:471-2.

5 Heeringa M, van Puijenbroek EP. Reversible dysgeusia attributed to losartan. Ann Intern Med 1998;129:72.

6 Stroeder D, Zessig, I Heath R. Angiotensin-II antagonist cGP 48933 (Valsartan). Ergebnisse einer doppelblinden, plazebo-kontrolierten Multicenter-studie. Nieren Hochdruckkrankheiten 1994;23:217-20.

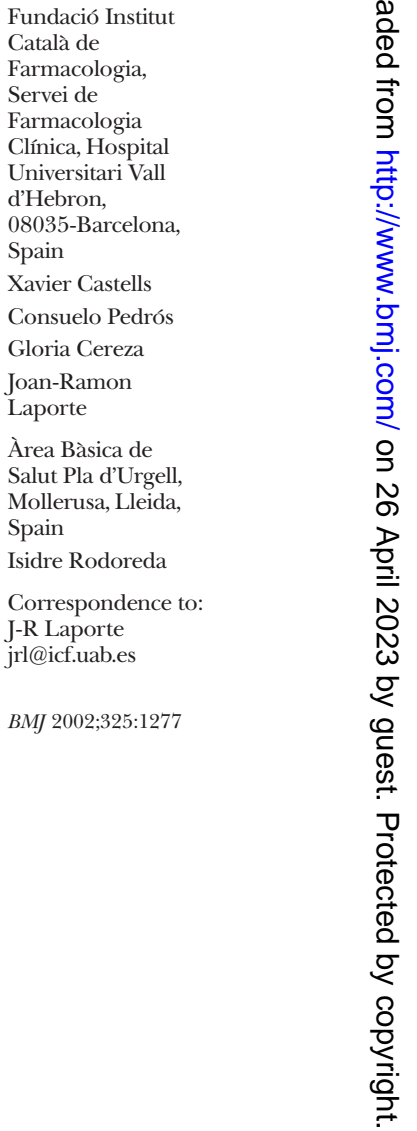

BMJ VOLUME 325 30 NOVEMBER 2002 bmj.com 